\title{
Humour Processing The Factors that Play a Role in Understanding Humour
}

Key words: humour processing, development of humour

\section{The Experience of Humour}

Humour is universal and, as a creative aspect of language, it is one of the most important topics in the study of communication. Humour is also a crucial component in many different contents of everyday life. Among other things, it can be seen as social glue that helps foster relationships (SAmson, 2013). Pedagogical trends in recent decades have shifted towards the promotion of a more relaued learning environment, with an emphasis on making learning fun. Justifications for the use of humour in education include improving attention control, promoting understanding, managing disruptive behaviour, creating a positive attitude towards the subject matter, and reducing ansiety. We owe "fun loving experiences" to our school-age children who display disorders such as fluency difficulties (AgIus, 2018).

Humour plays a role in coping with stressful situations in life on a daily basis, particularly when working with individuals with communication problems. Humour allows individuals to distance themselves from stressful situations, and to gain a degree of insight and objectivity (MANNING, 2009). We read: "Humor creates a relaned atmosphere and encourages communication particularly on sensitive matters" (McGHEe, Goldstein, 1977, cited in: MANNING, 2009: 36). Humour can be used to reduce stress and anriety for children who display communication difficulties, such as those with fluency disorders (AgIus, 2018). In this case, the stress associated with fluency disorders can increase in severity in certain conterts.

Humour has also been shown to support individuals with illnesses. One of the examples is the case of the patient coping with cancer who discovered that humour and hope were very important elements in her recovery (Dr David MIBASHAN, in his foreword to FEnWICK, 2004). Dr William Bucholz, an oncologist, wrote about the element of hope in a cancer patient: "Humor is like the seasoning that makes hope tasty. Humor adds the extra element for the will to live that goes beyond hope and that actually is the thing that turns an experience from tolerable to desirable" (KLEIN, 1998: 14). McGhee viewed humour

\footnotetext{
* e-mail: sandralevey@lehman.cuny.edu

** e-mail: joseph.g.agius@um.edu.mt
} 
as a form of intellectual play and argued that the level of humour a child is capable of understanding and producing at a given point in development depends primarily on the cognitive level of functioning achieved ( $\mathrm{RucH}, 2008$ : 65).

\section{Cognitive Skills and Processing Humour}

Cognition involves knowledge and intellectual capacity (Lever, 2011). These abilities allow children to: adjust to different elements, situations, and events; draw abstractions; and make sense of actions or events that are experienced. Social cognition allows children to determine what information is already known by a listener, what information is needed, and what possible misunderstandings might occur. It is the development of a theory of mind (TOM) that allows children to acquire social cognition and see things from other people's point of view. TOM also underlies the understanding that speakers intend to convey humour. TOM marks the cognitive skills of typically developing children, shown in the ability to take another person's perspective or point of view into consideration (BARONCohen, 2000; Paul, Landa, Simmons, 2014). Understanding humour reflects high-order cognitive processes, essential for understanding the social / emotional content associated with humorous concepts. This skill is based on the ability to understand someone else's mental state or intent (RHodes, BRANDONE, 2014).

Understanding humour also depends on a child's ability to recognise incongruity (an absurd or strange situation or action). Incongruity involves an event or story resulting in an illogical conclusion or action, such as a shoe used as a hat. Understanding the unenpected, incongruous action or event underlies the ability to understand humour (Souтнам, 2005). Another example of incongruity can be found in many knock-knock jokes, such as: Knock-knock. Who's there? Olive. Olive who? Olive you! [I love you!]. Incongruity is found in the fact that an olive cannot knock on a door. Processing incongruity within humour involves two stages: comprehension (stage 1) and appreciation (stage 2) (VRTICKA, BlAck, REISS, 2013). In the first stage, the listener must be able to detect incongruity. In the second stage, the listener must be able to integrate the new information with a positive emotional response. This process is supported by cognitive, emotional, psychological, and social abilities (MARTIN, 2007), along with the ability to recognise incongruity.

\section{The Development of Humour}

The development of humour appreciation started to be taken seriously in the 1970s and 1980s (Ruch, 2008). Paul McGhee (1979) reviewed the existing theories of humour development and put forward a four-stage model of humour development during childhood. Incongruity occurs when things do not agree with what is expected, given an absurd or unexpected action or comment. In the first stage (Incongruous Actions Towards Objects), children engage in pretend play, and new objects are used to represent other objects (a banana as a telephone). In the second stage (Incongruous Labelling of Objects and Events), language development supports children's humour production and pretend play. 
In the third stage (Conceptual Incongruity), conceptual thought development and humour is based on changing the features of objects or events (e.g. putting a sock on one's ear). In the final stage (Humour in Multiple Meanings), there is an understanding that alternative and ambiguous meanings exist for words (e.g. bear / bare).

There is a gradual development of understanding and producing humour. The social environment plays a role in the development of humour (HоICKA, 2014). Laughter is one of the first social vocalisations (after crying) produced by human infants (McGHeE, 1979). Initially, infants respond to adults who make odd noises or faces (MIREAULT, ReDdy, 2016); they begin to laugh at about 3 to 4 months of age, which indicates an early response to humorous behaviours or events (REDDY, 2008). Children begin to repeat actions that elicit adults' laughter (REDDY, 2008), such as making funny faces, playing peek-a-boo, and making noises and movements designed to elicit a response (e.g. kicking their legs).

In the first year of life, the response to humour generally involves adults' use of a squeaky voice, tactile stimuli (e.g. bouncing a baby on the adult's knee or lap), and other actions frequently performed by adults to elicit children's laughter (НогскA, 2014). At about 12 months of age, children enjoy silly actions, such as watching someone misuse an item (e.g. someone putting a bowl on their head to represent a hat). The use of incongruity appears at 18 to 24 months when children use one object to represent another. At about age 2, children invent jokes (Ногска, АкнтАR, 2011). Examples consist of handing an adult the incorrect object (giving a spoon when asked for a cup) or making up names for things (calling a cup a silly or another name). 3-year-old children are more likely to laugh when mislabelling items in this manner.

Older children enjoy puns and ambiguous meanings (e.g. She has bear feet versus bare feet) (McGHeE, 1980). Puns are the simplest form of humour, based on the use of visual or semantic similarity. Children begin to enjoy riddles at ages 3 to 4 (What do you call a rabbit who tells jokes? A funny bunny) (Sочтнам, 2005). For older children, humour often involves linguistic ambiguity, such as the example of phonological ambiguity that contrasts sick and tick (Why did the clock go to the doctor? Because he was tick). The appreciation of jokes generally emerges at age 2. Understanding and enjoyment of puns, satire, and ambiguous meanings emerge when children develop greater vocabulary skills at a later age (MCGHEE, 1979). Humour also plays a role in children's socialisation, with most research showing a relationship between play and humour (MCGHEe, 2013). Cognitive, language, social, psychological, and emotional skills are the factors that allow children and adults to process humour. The comprehension of abstract language is essential for understanding more compleu humour forms.

\section{Abstract Language and Humour}

Another element in the perception of humour involves the ability to understand abstract language. Abstract language involves reference to concepts rather than to more concrete, physical entities. The understanding of abstract concepts develops when children learn that words can have various meanings, such as dull, sharp, and shallow: That movie was really dull (not interesting or engaging), He looks really sharp (he looks very stylish), and 
I think they have a really shallow understanding of this problem (they do not have a deep understanding of a problem). The knowledge of abstract language meanings allows children to better understand figurative language, which consists of idioms, similes, metaphors, and proverbs. Figurative language also appears in riddles and puns, often found in children's books.

- An idiom is an expression with a meaning that cannot be identified by the words that are used. Idioms may be transparent or opaque. Idiom transparency involves a close relation between the figurative meaning and the literal meaning. For example, the idiom Don't trust them as they will stab you in the back is transparent as a stab involves an attack. The idiom They are barking up the wrong tree is opaque as the words do not involve a dog barking at an animal in a tree. Instead, the meaning involves someone who has the wrong idea or approach to a solution. Opaque idioms present more difficulty to younger children (Nippold, Duthie, 2003) because the words that compose these idioms give no clear cues to meaning. Children are able to understand transparent idioms by around age 10, while opaque idioms are not understood until around age 15.

- Similes make a comparison between two different subjects, such as He is as stubborn as a mule. The meaning of this simile involves someone's belief, behaviour, or opinion that is difficult to change, similar to the comparison with mules (an animal difficult to convince to move). Similes require the understanding of concepts, such as the meanings of words and the characteristics of the entities involved in the comparison.

- Metaphors make a comparison between two unrelated entities: The eram was a breeze (the exam was easy). Children may understand simple metaphors by age 6 (NIPPOLD, LEONARD, KAIL, 1984), with more abstract forms understood during adolescence.

- Proverbs express truths: A stitch in time saves nine (addressing a problem immediately prevents later greater efforts). Proverbs are not understood until a later age, such as adolescence. Proverbs also vary across languages, making it difficult from children from diverse cultures or language backgrounds to understand proverbs in a new language (RoseberRy-McKibisin, 2007, 2014).

- A riddle is a type of humour that has the form of a puzzle with a clever answer. Humour in riddles and jokes requires understanding that words may sound the same but are spelled differently and have different meanings (bear / bare) (BERNSTEIN, LEVEY, 2009). The basis for humour in children's riddles is based on the inherent ambiguity in the meaning of a key word (MCGHEE, 2018: 186). Riddles also require an answer, as shown in the following example (NIPPOLD, 2007: 242): Why can't the bicycle stand up by itself? Because it is two-tired. Additional examples of riddles follow:

What do you call an alligator in a vest? An investigator.

How many tickles does it take to make an octopus laugh? Ten tickles.

Why are teddy bears never hungry? They are always stuffed.

- A pun is a joke that makes use of the different possible meanings of a word. This type of humour is generally understood by older school-aged children. Enamples of puns follow:

A skunk fell in the river and stank to the bottom.

The chicken crossed the playground to get to the other slide.

The best way to stop a charging bull is to take away his credit card.

Fish are smart because they live in schools. 


\section{The Neurological Foundation of Humour}

Neuroscience research has found that humour is engaged by a network of cortical and subcortical structures. For example, the parietal-temporal-occipital areas have been found to be involved in detecting and resolving incongruity (VRTICKA, BLACK, ReISS, 2013). Euidence developed by fMRI research suggests that there are neurological bases to humour processing based on a cognitive-affective function (VRTicka, Black, Neely, Shelly, ReIss, 2013). This function comprises two stages. The first stage is the cognitive humour component that involves detection and resolution of incongruity, with activity associated with the parietal-temporal-occipital areas of the human brain. The second stage is the emotional humour component associated with positive feelings related to mirth / reward. This stage is connected with reward-related activity in the mesocorticolimbic circuits. The neurological basis of processing is necessary to process humour. Within certain disorders, this ability is absent.

\section{6. "Wit or Without" Humour in the Autistic Spectrum Disorder}

One group of people that encounters difficulties with humour are those with Autism Spectrum Disorders (ASD). Difficulty in understanding jokes could be mainly due to literal understanding and difficulty with irony and sarcasm, related to the process of resolving incongruities. Early research found that individuals with ASD enjoy the visual type of humour found in slapstick comedy and the less compler language found in simple jokes (Ricks, Wing, 1975). According to Mary E. Van Bourgondien and Gary B. Mesibov (1987), the jokes told by high-functioning adults with autism, such as jokes based on lenical or phonological incongruities, are on a lower humour stage than the individuals' actual age would imply. Vasudevi Reddy, Emma Williams, and Amy Vaughan (2002) found that children with autism enjoy being tickled and also enjoy slapstick humour. Errin JonES (2009) also found that children with autism produce and appreciate humour to a limited extent, such as simpler examples of humour based on rhyme, slapstick, and funny sounds.

Simon BARON-Cohen (1997) found children with autism to be less able to understand another person's intention to joke. Two studies presented jokes or cartoons with different possible endings. Participants with ASD chose the correct funny ending less often (Emerich, Creaghead, Grether, Murray, Grasha, 2003). Moreover, Andrea Samson and Michael Hegenloh (2010) demonstrated that individuals with ASD have a more detailand reality-oriented processing style. Interestingly, laughs produced by the children with ASD were more liked by others than laughs from the control group children. This result is most probably associated with the nature of ASD laughter to express genuine enjoyment, rather than the laughs expressing social motivations to influence others (HUDENKO, Magenheimer, 2012). A study by Catarina Silva, David Da Fonseca, Francisco Esteves, and Christine Deruele (2017) revealed that, at an explicit level, participants with ASD are able to enjoy and understand the humorous stimuli as much as typically developing participants. At an implicit level, however, the results suggest that humour processing may be especially content-dependent for participants with ASD. 
A study of high school aged students examined their understanding of jokes, with a comparison between students with ASD and those with typical development (Wu et al., 2014). According to the findings, students with ASD exhibited less comprehension of all types of jokes than the control group. These students were unable to comprehend nonsense and incongruity-resolution jokes, but enjoyed reading nonsense jokes. The students with ASD fauoured nonsense jokes that required less logical reasoning and homophones for double-meaning (e.g. bare / bear). The inability to process humour is consistent with the inability to perceive the mental states of other people. This affects the ability to process or understand the punch line necessary to get a joke (BARON-COHEN, 1997).

Hans Asperger (1944) described humourlessness to be one of the characteristics of individuals with Asperger syndrome (AS) (SAmson, Huber, Ruch, 2013), once considered to indicate a high functioning autism spectrum disorder. Using standardised assessments of humour, Andrea C. SAmson, Oswald Huber, and Willibald Ruch (2013) revealed that individuals with AS scored significantly lower on trait cheerfulness and higher on trait seriousness, both describing the susceptibility to humour. Furthermore, they scored low on scales related to social communication (affiliative humour, humour entertainment) and portrayed a more socially cold humour style. In addition, individuals with AS scored low on mean-spirited humour, and used less adaptive (self-enhancing) and more maladaptive humour styles (self-defeating humour). They also preferred "incongruity-resolution humor representing a more reality-oriented processing style" (SAMSON, HUBER, RUCH, 2013: 441).

\section{Discussion}

The development of humour begins when infants interact with those who employ odd noises or make silly faces, whereas toddlers enjoy and recognise incongruity (e.g. a bowl used as a hat). Older children employ humour in interaction with peers to develop and strengthen social relationships. The ability to appreciate humour helps create strong personal relationships. Adults use humour in a similar manner, while also employing humour in uncomfortable situations. Humour has been found to be a factor in supporting recovery for those with illnesses. To appreciate humour, a listener must comprehend, appreciate, and detect incongruity, and then respond positively to the speaker who conveys humour. The ability to appreciate humour requires cognitive, emotional, and psychological abilities, along with an interest in social interaction. However, some individuals lack the ability to appreciate humour, such as those with ASD. In this case, these individuals have difficulty with the more abstract factors associated with humour, along with the inability to perceive others' mental states intended to convey humour.

\section{References}

Aglus J., 2018: Shifting Perceptions: Using Creativity and Humour in Fluency Intervention. "Forum Logopedyczne" 26, pp. 49-61. 
Baron-Cohen S., 1997: Are Children with Autism Superior at Folk Physics? In: Wellman H., InAGAKI K., eds.: The Emergence of Core Domains of Thought: Children's Reasoning about Physical, Psychological, and Biological Phenomena. San Francisco, CA, pp. 45-54.

Baron-Cohen S., 2000: Theory of Mind and Autism: A Review. "Mental Retardation and Developmental Disabilities Research" 23, pp. 169-184.

Bernstein D.K., Levey S., 2009: Language Development: A Review. In: Bernstein D.K., TiegermanFARber E., eds.: Language and Communication Disorders in Children. $6^{\text {th }}$ ed. Boston, MA, pp. 28 100 .

Emerich D.M., Creaghead N.A., Grether S.M., Murray D., Grasha C., 2003: The Comprehension of Humorous Materials by Adolescents with High-functioning Autism and Asperger's Syndrome. “Journal of Autism and Developmental Disorders" 33 (3), pp. 253-257.

FENWICK C.R., 2004: Love and Laughter: A Healing Journey. Foreword by D. MiBASHAN. Muenster, SK.

Hoickа E., Акнtar N., 2011: Preschoolers Joke with Jokers, but Correct Foreigners. “Developmental Science" 14, pp. 848-858.

Hoicka E., 2014: Pragmatic Development of Humor. In: Matthews D., ed.: Pragmatic Development in First Language Acquisition. Amsterdam, pp. 219-238.

Hudenko W., Magenheimer M., 2012: Listeners Prefer the Laughs of Children with Autism to Those of Typically Developing Children. “Autism” 16 (6), pp. 641-655.

JONES E., 2009: Humour and Laughter in Children with Autism Spectrum Disorders. Dissertation. School of Behavioural and Social Sciences and Humanities, University of Ballarat, Victoria, Australia.

KleIN A., 1998: The Courage to Laugh: Humor, Hope, and Healing in the Face of Death and Dying. New York.

Levey S., 2011: Theories and Explanations of Language Development. In: Levey S., Polirstok S., eds.: Introduction to Language Development: Understanding Language Diversity in the Classroom. Los Angeles, CA, pp. 17-36.

Manning W.H., 2009: Clinical Decision Making in Fluency Disorders. $3^{\text {rd }}$ ed. Clifton Park, NY.

Martin R.A., 2007: The Psychology of Humor: An Integrative Approach. Burlington, MA.

McGhee P., 1979: Humor: Its Origin and Development. San Francisco, CA.

McGheE P., 1980: Humor: Its Origin and Development. New York, NY.

McGhee P.E., 2013: Humor and Children's Development: A Guide to Practical Application. New York, NY.

McGhee P.E., 2018: Comments on the Special Issue. "Humor" 31 (2), pp. 183-212.

Mireault G.C., Reddy V., 2016: Humor in Infants: Developmental and Psychological Perspectives. Basel.

Nippold, M.A., 2007: Later Language Development: School-age Children, Adolescents, and Young Adults. Austin, TX.

Nippold M.A., Duthie J.K., 2003: Mental Imagery and Idiom Comprehension: A Comparison of School-age Children and Adults. “Journal of Language and Hearing Research" 46 (4), pp. 788-799.

Nippold M.A., Leonard L.B., KaIL R., 1984: Syntactic and Conceptual Factors in Children's Understanding of Metaphors. “Journal of Speech and Hearing Research" 27, pp. 197-205.

Paul R., Landa R., Simmons E., 2014: Assessing and Treating Communication. In McPartland J., Klin A., Volkmar F., eds.: Asperger Syndrome: Assessing and Treating High Functioning Autism Spectrum Disorder. $2^{\text {nd }}$ ed. New York, NY, pp. 103-142.

Reddy V., 2008: How Infants Know Minds. Cambridge, MA. 
Reddy V., Williams E., Vaughan A., 2002: Sharing Humour and Laughter in Autism and Down's Syndrome. "British Journal of Psychology" 93 (2), pp. 219-242.

Rhodes M., Brandone A.C., 2014: Three-year-olds' Theories of Mind in Actions and Words. "Frontiers in Psychology" [online: https://static1.squarespace.com/static/56d88d0c0442624b79f94337/t/56e1c b2ba3360c4beb0694e1/1457638188496/; accessed: 06.01.2019.

Ricks D.M., Wing L., 1975: Language, Communication, and the Use of Symbols in Normal and Autistic Children. "Journal of Autism and Childhood Schizophrenia" 5 (3), pp. 191-221.

Roseberry-McKibian C., 2007: Language Disorders in Children: A Multicultural and Case Perspective. Boston, MA.

Roseberry-McKibian C., 2014: Multicultural Children with Special Language Needs: Practical Strategies for Assessment and Intervention. $4^{\text {th }}$ ed. Oceanside, CA.

Ruch W., 2008: Psychology of Humor. In: RAskin V., ed.: The Primer of Humor Research. Berlin-New York, pp. 17-100.

Samson A.C., Huber O., Ruch W., 2013: Seven Decades after Hans Asperger's Observations: A Comprehensive Study of Humor in Individuals with Autism Spectrum Disorders. "Humor" 26 (3), pp. $441-460$.

Samson A.C., Hegenloh M., 2010: Stimulus Characteristics Affect Humor Processing in Individuals with Asperger Syndrome. “Journal of Autism and Developmental Disorders” 40 (4), pp. $438-447$.

Samson A.C., 2013: Humor(lessness) Elucidated - Sense of Humor in Individuals with Autism Spectrum Disorders: Review and Introduction. "Humor: International Journal of Humor Research" 26 (3), pp. 393-409.

Silva C., Da Fonseca D., Esteves F., Deruelle C., 2017: Seeing the Funny Side of Things: Humour Processing in Autism Spectrum Disorders. "Research in Autism Spectrum Disorders" 43-44, pp. $8-17$.

Soutнам M., 2005: Humor Development: An Important Cognitive and Social Skill in the Growing Child. "Physical and Developmental Therapy in Pediatrics" 25 (1/2), pp. 105-117.

Van Bourgondien M.E., Mesibov G.B., 1987: Humor in High-functioning Autistic Adults. "Journal of Autism and Developmental Disorders" 17 (3), pp. 417-424.

Vrticka P., Black J.M., Neely M., Shelly E.W., Reiss A.L., 2013: Humor Processing in Children: Influence of Temperament, Age and IQ. "Neuropsychologia" 51 (13), pp. 2799-2811.

Vrticka P., Black J.M., Reiss A.L., 2013: The Neural Basis of Humor Processing. "Nature Reviews Neuroscience" 14 , pp. 860-868.

Wu C., Tseng L., An C., Chen H., Chan Y., Shin C., Zhuo S., 2014: Do Individuals with Autism Lack a Sense of Humor? A Study of Humor Comprehension, Appreciation, and Styles among High School Students with Autism. "Research in Autism Spectrum Disorders" 8 (10), pp. 1386-1393.

Sandra Levey, Joseph Agius

Humour Processing

The Factors that Play a Role in Understanding Humour

Summary

This article addresses the skills involved in processing humour. Both adults and children enjoy puns, jokes, and riddles and employ humour in interaction with friends. Factors that contribute to 
understanding humour involve cognition, the ability to identify a speaker's intent to convey humour, and the desire to engage in social interaction. Humour can be found in all countries across the globe, though cultural and linguistic differences may influence what listeners consider humorous. Moreover, some listeners have difficulty processing or understanding humour. The article also outlines studies investigating humour understanding and appreciation in relation to autistic spectrum disorders. 